
develop to leverage improved outcomes for their institutions. Abundance, an organizational state achieved through leveraging, develops against a backdrop of context and ideologies that must be addressed to effect change.

\title{
Leaders, Leveraging, and Abundance: Competencies for the Future
}

\author{
Richard L. Alfred
}

Leadership, as it is practiced today in community colleges, has taken three brilliant ideas to excess and made them into guiding ideologies. The first is growth, a means for gauging organizational legitimacy and success that has eclipsed other means. The second is complexity, which has gained acceptance as a structural necessity for managing mission sprawl. The third is effectiveness, which has become an end in itself rather than a tool for enhancing performance.

Each of these ideas began as a solution to a pressing problem-how to create more value for more people. Over time, institutions and leaders have clung to this philosophy, but the makeup of the problem has changed. Resources and capacity are no longer adequate to support growth. This mismatch has caused problems of such urgency that leaders and stakeholders alike are beginning to ask questions about the community college business model. Are community colleges for everyone? What is the future of the open door? Should the mission be altered to accommodate resources? What is the basis of organizational success in a changing landscape? Triggered by conditions largely beyond institutional control, the "do more with less" business model is under scrutiny as inherently unworkable. Also under scrutiny is the efficiency of our colleges, the benefits they deliver to constituencies, and the proficiency of leaders.

It's not that the business model is broken or ineffective; generally speaking, community colleges remain the most efficient of organizations 
for moving people between schooling and jobs. But keeping them on track will depend on our ability to develop leaders with future-focused skills. This task will not be easy. It will require rethinking runaway ideologies such as growth and complexity that are of signal importance in our colleges today and identifying evolutionary ideologies that will be important tomorrow. Among these new ideologies are abundance and leveraging - the road to effective leadership will run through them.

The objective of this chapter is to question and rethink foundational principles for leadership in today's community colleges. The chapter begins by examining the changing context for leadership. Forces outside of colleges that demand new skills and competencies are described along with runaway ideologies that shackle leaders by limiting their creativity. Among the skill sets that future leaders will need are an understanding of abundance and a capability for leveraging. Abundance, a state achieved by an institution when its resources are leveraged to a level beyond reasonable expectation, will be a hallmark of high-performing institutions in a postrecessionary economy. Leveraging, the achievement of increasingly positive outcomes with increasingly meager resources, will be a capability that leaders must have to get the most out of institutions with austere resources.

No chapter on leadership would be complete without a list of desirable attributes in leaders. Generally, I do not subscribe to lists of this type; value can be found in almost any attribute if circumstances are right. Toward the close of the chapter, however, I depart from this practice and include my own list of attributes. Why? Because the basis for abundance is rooted in a select group of attributes. The chapter closes with a description of these competencies, where leaders who possess them might be found, and what institutions can do to develop them from within.

\section{Changing Context for Leadership}

Prior to the onset of the recession in 2007, the future for community colleges was challenging but at least comprehensible. Now it is a whirlwind of contradictory forces of growth and reduction, access and completion, and demand and decline. Most colleges are encountering opportunities for growth in a market loaded with learners needing more to find their way in the new economy. Counterbalancing these opportunities, however, is uncertainty about the resources colleges will have to support growth and their capacity to absorb more learners. These forces will have a significant effect on how colleges operate in the future.

The New Normal. Substantive change in the landscape for community colleges can be traced back to the onset of the recession and the election of Barack Obama as president. In 2012, the nation is five years and counting into a recession that has profoundly disrupted every facet of American life. Mobility ground to a sixty-year low in 2010 as unemployment, plunging home values, and declining confidence in the economy 
forced people to delay major life decisions. The decline in home prices between 2005 and 2009 wiped out a vast amount of wealth and sent consumer spending spiraling downward.

The economy showed signs of rebounding in the first quarter of 2011, only to be stymied by slow job growth and delayed passage of debt ceiling legislation. Volatile financial markets, lingering high unemployment, a widening European debt crisis, and eroding consumer confidence combined to create a recovery that looked more like a recession with the potential for relapse into a crisis. The impact of the Great Recession continues, with a slow-moving recovery that could last for years. The crash of the housing market, high credit card debit, and uncertainty about job security have curbed consumer confidence. A nation long defined by exuberance and a belief that tomorrow will be better has turned gloomy about the future. This "new normal" is something heretofore not manifested in the American psyche.

Dynamic of Contradiction. In every cloud there is a silver lining. Opportunistic investors have long used economic downturns as buying opportunities. Businesses have used the urgency that accompanies slumps to mobilize innovation and renewal. Community colleges have experienced dramatic enrollment gains in periods of economic recession. The current recession is no exception (National Student Clearinghouse Research Center, 2011). Enrollment of traditional-age students in community colleges grew significantly between 2006 and 2009, moving from 42 percent to 45 percent of all first-time students (National Center for Education Statistics [NCES], 2009). Yet this upward trend reversed in 2010. Growth can be attributed to students who in better economic times might have chosen to attend other (and costlier) types of institutions, those who would have joined the workforce after graduating from high school, and those returning to college to retool after becoming unemployed. Decline can be attributed to capacity strain at community colleges and early signs of economic recovery.

Opposing forces of growth and reduction can be likened to accelerators and decelerators. Accelerators facilitate movement by encouraging change, whereas decelerators impede movement by constricting the resources available to institutions. Contradiction is experienced as colleges working with lean resources must find ways to serve learners wanting more and better service at reasonable cost. In effect, decelerators become accelerators when leaders must find creative solutions to adversity (Alfred, 2011).

If the economy moves into a sustained recovery, a scenario driven by forces of deceleration is unlikely. In normal times, people return to a pattern of consumption marked by increased spending during a recovery. The taxes they pay replenish state treasuries, and some of this money finds its way into community college operating budgets. In the "new normal," however, states will change how they do business. New revenue policies and 
appropriations criteria will be adopted as a hedge against future year downturns, and colleges will see less money in their budgets.

Summary. For community colleges, the implication of simultaneous conditions of growth and reduction will be change or die. While coping with the effects of deceleration fueled by a lingering recession and diminished resources, they will simultaneously be coping with forces of acceleration fueled by burgeoning learner demand and intensifying calls for accountability. Learners will want more and better service, and policymakers will want evidence of better results. For institutions and leaders this will mean innovation-finding new and better ways of delivering service, creating efficiencies and cost economies, and improving outcomes. It will also mean doing things that were heretofore considered unpalatable: changing the business model, procuring significant private sources of funding, redesigning organizational structure, collaborating with competitors, reengineering culture, streamlining systems and processes, and learning how to change through substitution.

\section{Runaway Ideologies}

The concept of "runaway" ideologies and the structure of the analysis to follow build on the work of Meyer and Kirby (2012). Using the example of the peacock and constructs from evolutionary biology, Meyer and Kirby describe how the tails of peacocks have become ever more flamboyant over time due to one simple fact: peahens exhibit a preference for long-tailed peacocks. A larger tail is a marker of a healthy male that will produce healthy offspring. Consequently, well-feathered males are more likely to pass along this trait. Over many generations, the tails of peacocks have grown larger, but the peacock population has dwindled to the point where human intervention has been necessary to save the species. A larger tail is heavy and more easily seen, thereby making the owner easier prey for enemies. Evolutionary theorists describe this phenomenon as "runaway selection" - a form of biological suicide.

In the case of community colleges, what organizational ideologies might they have adopted that would produce early success but possibly later failure? Put another way: Could there be a mismatch between ideologies of growth, complexity, and effectiveness in today's landscape and organizational success in tomorrow's landscape?

Consider how runaway ideologies might work in community colleges. For instance, a process of redesigning curricula to produce higher student completion rates may result in a streamlined curriculum in which learners are able to finish more quickly, but with skill sets that do not position them effectively for long-term job success. The problem is exacerbated when students press for course requirements narrowly focused on job skills, rather than for general education courses that equip them with soft skills necessary for long-term job success. As job requirements change, graduates are 
left unprepared. In most cases, misalignments are easy to spot and don't persist for long. The more insidious problems arise when an organizational ideology is valid and leads to early success only to become obsolete as conditions change. This notion of an ideology's becoming obsolete, even counterproductive, over time brings us to growth.

The Obsession With Growth. For years, among the most frequently asked questions in community colleges has been "What's our enrollment compared to last year?" rather than queries about student retention and completion rates, operating costs, and student outcomes in work and further education. The roots of a focus on growth harken back to fifty years ago when community colleges were established at a rate of one per week and enrollment growth was the fast lane to legitimacy for fledgling institutions. Rapid growth made a statement about institutional vitality and put community colleges on the map. The cost of growth was cheap-sections could easily be added to enroll more students, temporary space could be found to offer more courses and services, and lower-cost part-time instructors could be hired to teach classes. Furthermore, there was upside protection for growth through enrollment-driven state aid formulas.

Growth was not the overall objective; rather it was part of a mission to put postsecondary education access within everyone's reach. But the opportunity to build identity and visibility through growth was attractive, and over time it became an ideology. Leaders working with resources needed a credo to guide decision making, and growth filled the bill quite nicely. Thus was born a runaway ideology that to this day drives the commitment to growth as a way of demonstrating institutional (and leader) success.

The recession has only intensified the need to perpetuate growth and encouraged attention to efficiency to get the most out of capacity. Enormous weight continues to be given to the "more" associated with growth, but comparatively little to the "better" associated with other indicators of performance. Student completion has only recently become a policy issue for community colleges, and value added is just beginning to come into focus. Performance assessment is beginning to change, but noticeably absent are indicators that gauge the intangible side of what institutions do, particularly their effect on people. This runaway ideology will not be curbed until other success criteria counterbalance the obsession with growth. A challenge for community college leaders today and those who will lead tomorrow is identifying success criteria that have enough weight to supplant growth as the barometer of institutional success.

The Surrender to Complexity. Complexity is a correlate of growth. The easiest and quickest way to accommodate growth when resources are tight is to increase workload and expect more from people. For the most part, however, growth is accommodated through change in infrastructureadding management divisions and layers, systems and processes, and people and positions. These additions lead to more complexity in organizations. 
Complexity results in problems that were not part of a smaller and simpler organization. For example, communication and decision making must now move through layers and processes where none previously existed. The ubiquitous nature of these changes results in staff's accommodating change rather than questioning it. Thus, the effect of complexity is to enable the institution to accommodate growth, but in so doing to contribute to lowered morale and satisfaction. The result is an institution working against itself as allegiance shifts from the institution to the work unit. By separating individuals into units that may not interact, work units-commonly known as "silos"-foster impersonal work environments. Contrast this with the experience of personnel on a small satellite campus distanced from other campuses and the central office of a large community college district. Everyone on campus is known, communication is more apt to be face to face, and silos are mitigated by compact size.

To portray complexity as an ideology is not to say that it must be eliminated-that is all but impossible. In a growth-oriented enterprise the way to manage complexity is not to embrace it but to question the underlying structures and assumptions guiding practice. The challenge for community college leaders today and tomorrow is not one of working with complexity, but of finding and creating simplicity.

The Means-Ends Inversion of Effectiveness. In organizations it is important to distinguish between the means or process of doing something and its end or outcome goal. An illustration of a fictional case study highlights this tension. Inward Community College is a large institution in a suburban community with a lucrative tax base. Since its establishment in 1964, Inward has maintained a steady course in pursuit of its mission of preparing students for transfer, responding to business and industry needs, and providing programs and services to the community. The college has benefited from strong community support, increased enrollments, and taxpayer approval for funding.

Inward has invested significant resources in the physical plant, retrofitted facilities to stay abreast of technology, hired credentialed faculty and staff, forged linkages with employers and $\mathrm{K}-12$ school districts, and committed itself to a culture of evidence by designing and implementing a comprehensive effectiveness model. The focus of effectiveness, however, is not on continuous improvement-it is on the accountability mandates of external agencies. Though reams of data exist, they do not serve a useful purpose.

The milieu of bliss unraveled in 2011, when Inward suffered a significant enrollment loss and unprecedented decline in local tax revenue caused by declining housing values. Tuition increased by 5 percent to offset lost revenue, and Inward found itself in a horse race for market share with regional four-year colleges. Here the impact of using data for reporting purposes rather than internal improvement became evident. Inward was not 
able to mount the improvement initiatives necessary to stave off competition from rivals. Beyond its utility for fulfilling the effectiveness mandates of external agencies, effectiveness had no real purpose at Inward. For its competitors, effectiveness was a means to an end of continuous improvement. Inward's approach to effectiveness is a classic example of what might be labeled convoluted ideology. By gathering data and failing to use it for continuous improvement, Inward converted effectiveness into an end in itself.

There are three important lessons implicit in the experience of Inward. First, leaders will need to understand the importance of means-ends alignment and resist the temptation to substitute means for ends. Second, leaders will need to understand the changing basis of competition and the speed at which rivals move. Rivals are moving faster and setting the bar higher with each passing year and cannot be taken for granted. Ideology becomes convoluted when leaders develop a false sense of security from advantage that worked in the past but not in the present. Finally, leaders will need to understand the growing importance of strategy and of differentiation. An institution without a clear strategy that distinguishes it from rivals is headed for trouble. Cost and convenience-the mainstays of community college strategy for decades-will not be sufficient in the future to maintain advantage. By implication this leads to a question that every leader will need to ask and answer: What will be the source of advantage in the future, and how can effectiveness information be used to locate and establish advantage?

These ideologies prompt questions about the emphases that command leader attention and commitment and how effectively these emphases will serve institutions in the future. We know that countervailing forces of growth, resource decline, and accountability are changing the playing field for community colleges. Will prevailing ideologies of growth, complexity, and effectiveness be sufficient to propel community colleges to high performance in the future? Emerging ideologies of abundance and leveraging provide an alternative.

\section{Abundance and Leveraging}

Abundance and scarcity are competing mind-sets in virtually all organizations. How these mind-sets manifest themselves in community colleges have much to do with the ease or difficulty leaders experience in managing an institution. Described simply, some individuals live in a world of scarcity-a world in which resources and opportunities are limited and must be acquired and protected. The scarcity mind-set is a zero-sum game in which one wins at the expense of another. The fear of loss is a driving motive. Losing what one has, losing out on possibilities for getting more, getting less than what one wanted or expected-these are the ingredients of scarcity. 
Others live in a world of abundance. Their underlying view is that resources and opportunities are unlimited. To the individual subscribing to abundance, opportunities and challenges must be embraced and pursued. The worst thing one can do is become attached to the status quo because possibilities abound. The abundance mentality involves a win-win mindset-there is plenty for all, and we can achieve more together than apart. Abundance and scarcity serve as endpoints on a continuum in which leaders may have a variety of perspectives based on their location on the continuum.

For faculty, this continuum might be evidenced by instructors who view their position as one of entitlement due to longevity, whereas instructors holding a different position might embrace change and opportunities to bring innovative teaching strategies into classroom teaching. Both instructors have a place in the institution, but they are working with different value systems - one of scarcity and the other of abundance. What will the contribution of each be to student success? In the management arena, the increasingly common saga of presidents in neighboring institutions working to reverse an enrollment dip following several years of unprecedented gains reveals differences in outlook and approach. One president is focusing on a short-term marketing strategy to recoup lost enrollment, while the other is developing a long-term strategy to bring new markets to the college. Both strategies are important. Which is likely, however, to be most effective over the long run?

Leaders in an era of rising demand and reduced resources need to become adept at doing more with less. They will need to generate new sources of revenue to support growth, increase the capacity and productivity of staff, win the war for talent with fast-moving rivals, build cultures that embrace innovation and change, and create networks that enable institutions to pursue opportunity. They will be challenged to develop new organizational designs to get in front of change, and they will need to think differently about organizational success. A tool to achieve these outcomes is leveraging - an institution's capacity to achieve superior performance by optimally using its resources.

The principle underlying leveraging is simple: leaders who want to grow institutions with limited resources will need to use current resources more effectively. The key to leveraging, however, is motivating people to effort beyond a reasonable level of expectation. Leveraging, therefore, is not about adding resources-people, money, and technology_-but doing more with what an institution already has. It is the basis of abundance (creating more), and its polar opposite is scarcity (coping with less). Leaders with a capability for leveraging value strength and achievement (positive deviance) in contrast to identifying and solving problems (negative deviance). There are distinct competencies that contribute to a capability for leveraging, which can be developed in leaders. They are identified below in the context of landscape changes that all community colleges are experiencing. 


\section{Competencies for Leveraging}

For more than four decades, there has been consensus about the kinds of experience community college professionals must have coming into positions of leadership, the personal attributes that give one the appearance of a leader, and the places and positions in which leaders are groomed and formed. Yet change is so rapid today that one leader cannot hope to keep abreast of all developments, much less be responsible for the innovation needed to remain at the forefront of the market. In today's community college, leaders relying on authority alone are not going to be around long.

Colleges require leaders with the intellect and skills to tackle the ideological issues described earlier-growth and complexity, effectiveness and organizational success, and abundance and scarcity. A list of traits alone will not address all these challenges. There are overarching attributes, however, shared by leaders who have this capability for flexible leadership (Alfred, Shults, Jaquette, \& Strickland, 2009).

Visioning and Optimization. Effective leaders generate visions for the institution, which involve creating a compelling image of the future and a college's place in the future-what it could be and, more important, what it should be. Leaders skilled at visioning are able to get staff excited about the future. They use stories and metaphors to paint a vivid picture of what a college could be, even if they don't have a clear plan for getting there.

Inventiveness. Leaders need creativity to transform a vision into reality. Even the most compelling vision will lose its power if it floats unconnected above the everyday reality of organizational life. Inventive leaders have the ability to relate vision to what people are actually doing and to give it legs through the eyes and actions of staff.

Relating and Inclusiveness. Leaders generate support for initiatives through earnest and meaningful interactions with staff. Listening with the intent of understanding thoughts and feelings and celebrating success are part of trust building. Integral to the relationship between leaders and staff is something that can best be called an "inclusion factor." Effective leaders do not let size and complexity get in the way of involving staff in decision making.

Simplicity. Conversations with leaders in abundant institutions reveal a commitment to simplicity that is expressed in two basic ways: (1) don't overload the system; and (2) help people understand what is going on by making systems, processes, and communication simple. Leaders in these institutions invoke transparent decision making. They relate the contribution of individuals to institutional performance by working to identify what is important in performance and restricting measurement to mainstream indicators.

Identifying and Developing Talent. Colleges operating in a knowledge economy have little hope of achieving high performance unless leaders initiate and sustain efforts to acquire, train, and retain the best 
talent. Effective leaders are compulsive talent scouts. They look for talent in unusual places both inside and outside of the institution, they do not permit stereotypical qualities to dictate what they look for in leadership, and they work nonstop to identify and develop talent. Much of what will go into developing successful leaders in the future will involve "fit"matching of individual, context, and culture.

Creating and Maintaining a Sense of Urgency. Effective leaders know that change begins with an uncompromising look at an institution's circumstances, its resources, and its performance. Creating urgency allows for critical introspection and moves staff out of their comfort zone. These leaders are engineers of motivation and use this to impel instructors and staff to move beyond yesterday's successes.

Collectively these attributes are the building blocks of abundance. By focusing on the ability of leaders to envision a desired organizational future state, to motivate and inspire staff, and to achieve and maintain peak performance, they enable an institution to leverage its resources. They stand in stark contrast to ideologies of growth and complexity, which drive leader behavior and actions in colleges today.

\section{Leading for Abundance}

Finding leaders is increasingly difficult today. Qualified candidates are no longer in abundant supply in the usual places and the war for talent is fierce. Finding individuals with leadership potential is becoming, or will become, the name of the game, but this game will be played in unconventional places with people who defy conventional stereotypes of leadership. For this reason, it is worth rethinking our image of the community college leader and how and where a person will acquire the attributes to become one. We may find that it's through experiences not usually associated with leader development and in places other than community college campuses.

Invisible to Visible. For one reason or another, many talented individuals inside the ranks of community colleges haven't been viewed as potential leaders. Often this has been because of explicit limitations-for example, access to tools such as social networks, fast-track training programs, stretch assignments, and capable mentors who prepare individuals for positions of influence. More subtle, however, is the influence of what Linda Hill at Harvard University (Harvard Business Review Editorial Staff, 2008) has labeled "stylistic" limitations-attributes of personality that don't fit the conventional image of a leader. We observe this in people who are overlooked for top leadership positions because they don't exhibit the takecharge, direction-setting behavior we often associate with leadership.

The increasing size and complexity of community colleges demands a more inclusive, collaborative style of leadership. This requires leaders who, among other things, are comfortable with sharing power, able to see extraordinary potential in ordinary people, and capable of making deci- 
sions with a balance of idealism and pragmatism (Harvard Business Review Editorial Staff, 2008).

Developing Leaders From Within. Leaders are in abundant supply if we are able to suspend preconceptions about the way leaders look and act that blind us to individuals with leadership potential. For tomorrow's leaders, we'll need to look for individuals with a capacity to embrace risk, to inspire a team, to motivate others to optimum performance, and to plant seeds that become others' ideas. Individuals who like people, possess attributes of transparency and authenticity, and have a passion for innovation are likely candidates for leadership. In addition to looking inside for leaders, there are personnel outside college walls who are prepared to lead by virtue of experience with austere resources, customer sensitivity, and high performance in service organizations-in particular, developing professionals in hospitals and health organizations, small-scale entrepreneurial businesses, nonprofit organizations, and social services.

Leading From Behind. Leading from behind can be likened to an experienced coach removing herself from the bench and watching her team play from a distance. The best players set the pace that others follow, not realizing that all along they are being directed from behind by coaching. This exemplifies tomorrow's community college leader: someone who knows how to create a context or culture in which others are willing to lead. The coaching metaphor also hints at the ability of a team to lead on the basis of its own initiative rather than waiting for a command. In Hill's view, this capability is more likely to be developed when leaders conceive of their role as creating the opportunity for collective leadership, in contrast to merely setting direction.

Leading from behind requires a shift in emphasis in what is expected from leaders and how they view their role. Institutional direction is not always clear in a rapidly shifting landscape. And complexity adds a new dimension to the functioning of community colleges that makes the leader as expert practically impossible. Let's use the example of visioning to see how leading-from-behind might work in a community college. Visioning begins with the president describing the purpose of the process, the themes it might incorporate, and the campus and community stakeholders who could be key contributors. The process unfolds with campus and community groups coming together in listening sessions to create ideas about the future. These ideas are charted and examined by the leadership team and become a network of ideas for formulating a vision that were not available to the team at the beginning of the process. The resulting vision is a product of collective thought-of leading in front upon the initiative of the president and from behind throughout the process.

\section{Parting Advice}

Developing the competencies needed to lead tomorrow's colleges requires experience with challenging situations that defy solution. Lead-from-behind 
skills are particularly important, and one way to develop them is through experience outside of institutional boundaries in collaborative settings where the effort of many is required to achieve a goal (Harvard Business Review Editorial Staff, 2008). Learning to work with a diverse group of peers on a team that does not have a designated leader differs in important ways from the early work experience of a college staffer reporting to a line administrator. When individuals work with others who are different from themselves in a setting that is unfamiliar they open themselves to new learning and they also have the opportunity to self-select as leaders. These are the leaders who are invisible today, but visible tomorrow.

Tapping invisible leaders within the organization will help widen the leadership pipeline and may have surprising results. The future of leadership in community colleges will depend to a significant extent on the ability of institutions to identify, not overlook, extraordinary potential for leadership that resides in ordinary people.

\section{References}

Alfred, R. L. "The Future of Institutional Effectiveness," in R. B. Head (ed.), Institutional Effectiveness. New Directions for Community Colleges, no. 153. San Francisco: Jossey-Bass, 2011.

Alfred, R. L., Shults, C., Jaquette, O., and Strickland, S. Community Colleges on the Horizon: Challenge, Choice or Abundance. Lanham, Md.: Rowman and Littlefield, 2009.

Harvard Business Review Editorial Staff. "Where Will We Find Tomorrow's Leaders? A Conversation with Linda Hill," Harvard Business Review, Jan.-Feb. 2008, pp. 1-7.

Meyer, C., and Kirby, J. "Runaway Capitalism." Harvard Business Review, Jan.-Feb. 2012, pp. 66-75.

National Center for Education Statistics. Digest of Education Statistics, 2009. Retrieved May 28, 2012, from nces.ed.gov/pubs2009/2009020.pdf]

National Student Clearinghouse Research Center. Community College Enrollment Trends: Before, During, and After the Great Recession. Herdon, Va., 2011. Retrieved May 28, 2012, from www.studentclearinghouse.info/signature/1/NSC_Signature_Report_1.pdf

RICHARD L. ALFRED is emeritus professor of higher education at the University of Michigan and founding director of the Center for Community College Development. 